\title{
Analysis on Inheritance Characteristics of Chinese Traditional Crafts and Its Influence
}

\author{
Hongshan Chen \\ Henan University of Technology \\ Zhengzhou, China
}

\begin{abstract}
Chinese traditional craft is a very important part of traditional Chinese culture, and is the main research content in Chinese art field, which plays an irreplaceable role. For the time being, Chinese traditional crafts gradually show the following characteristics: oral imparting with physical instruction, distinctiveness, vivid and alive form, and differences in different regions. At the same time, it has experienced the evolution of the workshop production. In recent years, Chinese traditional crafts gradually develop toward the mechanized and industrialized production. And the development trend will directly influence the protection and inheritance of Chinese traditional crafts. Therefore, it has an important practical significance to clarify and analyze the actual influences and the evolution characteristics of Chinese traditional crafts for the further development.
\end{abstract}

Keywords-traditional crafts; inheritance characteristics; influence

\section{INTRODUCTION}

The Third Plenary Session of the 18th Central Committee of CPC again put the cultural system reform on agenda. The government has gradually transformed the trend from the starting handling culture to the managing culture, which is conducive to the industrial development and the visual communication of Chinese traditional culture. At present, Chinese traditional craft is a unique expression form of arts, which has a very significant meaning in the social development. It is a guarantee to improve our cultural soft strength and protect intangible cultural heritage to analyze the inheritance characteristics and influences of Chinese traditional crafts ${ }^{[1]}$.

\section{ANALYSIS OF INHERITANCE CHARACTERISTICS OF CHINESE TRADITIONAL CRAFTS}

\section{A. The Oral Imparting with Physical Instruction Inheritance Way}

Traditional craft mainly relies on oral imparting with physical instruction to complete continuation, which is an experienced technique. In addition to oral imparting with physical instruction, some traditional crafts are spontaneously continued through teaching by personal example as well as verbal instruction among the mass. At the same time, it also includes the continuation method of generation-to-generation inheritance which is passed down through ancestors or mentors.
Generally, in modern production practice activities, elderly craftsmen teach their apprentices or descendents by personal example and verbal instruction about raw material selection, storage and transport management, production and processing, and so on. In the explanation and demonstration of traditional crafts, apprentices will further grasp and understand the knowledge taught by the elderly craftsmen. Then they participate in practical activities, and thus grasp this experienced technique, and pass down to the next generation.

Take the making process of bamboo paper for example. The most distinctive is the making process of Fuyang paper. Raw material of Fuyang paper mainly is current-year tender moso bamboo. The making of Fuyang paper includes 72 large and small procedures, such as, pulping and papermaking. In the inheritance of traditional Chinese paper-making craft, Fuyang paper effectively formed a series of distinctive making techniques. The most significant is "human urine fermentation" "2], which is one of special techniques in making Fuyang bamboo paper. Other bamboo paper productions don't use this method. The involved techniques are all taught by experienced masters who teach students with oral imparting and physical instruction. Students need to practice for a long term, so that they could grasp them and then pass down to the next generation. In the making process of Fuyang paper, the busiest link of the factories is to peel the bamboo and use it as raw material. Affected by time and other various factors, all newborn moso bamboos shall be cut in a short period. Generally it is within one month. At same time, the processing of raw material still is obviously limited by time. If it surpasses the time limit, the raw material will be overdue. It directly affects the quality of paper. To process bamboo is a very complicated craftsmanship, which needs workers to practice over and over in order to grasp the correct operating methods of this procedure. Thus, they can master their own ability, realizing the inheritance of the traditional making technique ${ }^{[3]}$.

\section{B. Vivid and Alive Inheritance Form}

In certain territorial scope, people's activities will directly influence the inheritance of the intangible cultural heritage of traditional craft. The inheritance of the intangible cultural heritage of traditional craft directly is affected by the mode of production and way of life in certain region, so the traditional crafts are inherited livingly. No matter in which region, the traditional craftsmanship shall be completed through activities of people. In further practices, people further perfect the traditional craftsmanship and make it scientific. If immediately 
terminate the inheritance activities, it will directly affect the dynamic performance of traditional crafts and the innovative function and reservation function of traditional crafts. They may disappear. The traditional crafts are not alive, but the making techniques of traditional crafts are alive. Therefore, the traditional crafts present an obvious flexibility under the influence of living techniques ${ }^{[4]}$.

Take Miao silver forging techniques in Guizhou as an example. This traditional craft is mainly distributed in the southeast of Guizhou. Miao silver forging technique mainly includes two inheritance forms. One is the wandering inheritance form. The other is the fixed-point inheritance form. It is obviously vivid and alive. For the wandering form, silversmiths mainly take family as workshop. In farm slack season, they go outside for business. In general, each silversmith has his/her own professional route. They can complete with other branches and people if they know each silver ornament pattern and sub-pattern, and are familiar with the making procedures of silver ornament. They will be handy with facility. For the fixed-pointed form, silversmiths make silver ornaments at home. This inheritance form mainly is carried out in a relative closed condition. Customers generally are of their own branch or people. The fixed-point inheritance form is also known as the silver inheritance within their own branch ${ }^{[5]}$. The distribution of silversmiths can be effectively adjusted according to regional environment and actual market demand.

\section{The Distinctive Inheritance Soil}

In the inheritance of intangible cultural heritage of traditional craft, its soil cannot be copied or implanted, and it cannot reborn. So, the inheritance of the intangible cultural heritage is the basis of the inheritance of traditional crafts, which plays an importance role in the inheritance of traditional crafts. The distinctive inheritance soil of different regions and people directly affect the distinctiveness of the inheritance of traditional crafts. At present, the classification of traditional crafts in our country is still quite a lot. Even in the same category, there are various traditional crafts in different regions. Take Chinese four famous embroideries for example. The four famous embroideries are all in the class of embroidery craft. But their differences are very obvious. It is mainly because of their existing in different regions. They possess their own characteristics. First is Sichuan embroidery. The most obvious characteristic of Sichuan embroidery is folk auspicious words. It uses traditional patterns, and flower, bird and fish patterns, with clear thinking, neat and orderly needling. The surface is very flat and bright, just like a knife-cutting face ${ }^{[6]}$. Second is Suzhou embroidery. The obvious characteristic is the main built-in stitchwork form. In the process of embroidering threads, the stitchwork is flexible, with exquisite works and crisp lines. The third is Hunan embroidery. The most obvious characteristic is its strong texture. It is with vivid pattern, and of bold and unconstrained style. The last is Guangzhou embroidery. In fact, it includes two big categories, velvet embroidery and gold embroidery. The most notable characteristic of velvet embroidery is colorful colors with beautiful flower, bird, fish and insect pattern. The main characteristic of gold embroidery is its splendid and brilliant colors and elegant bearing, for it is mainly embroidered with gold threads.

We have a lot of traditional crafts. Under the same category, traditional crafts of different people are also very different. There are many consistencies in potting crafts. In region of Li people in Hainan Island, they use clay lath coiling method, clay piece pasting method, fast-wheel throwing method to complete the blank forming in the potting craft. With different conditions, the direct impact is the difference between soils and their inheritance. In Yunnan Xishuangbanna Dai Autonomous Prefecture, they generally use the toe-poking slow-wheel method, no-reel blank forming method and the hand-poking reel method to complete the blanking forming. Some of them are still widely spread, mainly because of their very prominent use value.

\section{THE INFLUENCE OF THE INHERITANCE CHARACTERISTICS OF CHINESE TRADITIONAL CRAFTS ON ITS PROTECTION}

Chinese traditional craft is a very important part of Chinese traditional culture. The bearer of traditional manufacturing crafts can stimulate people with certain emotional force. Our traditional craftsmanship mainly comes from the folk, so it is a very representative grass-roots culture and local culture type. At the same time traditional craftsmanship also combine the emotions of people and include the most sincere feelings of the people, composing China's rich and colorful cultural patterns. In any living regions in China, there are obvious inheritance tracks of traditional craftsmanship. As long as the shadow of traditional crafts exists, it will produce a kind of nostalgia complex despite of the damage of the inheritance culture form of traditional crafts and other reasons. For example, Chinese traditional printing and dyeing technique, the blue prints, is till spread at present, and has derived a lot of new products. We no longer use the traditional printing method, but effectively combine manual work with mechanized production. On the basis of industrial production, we further reduce the cost, protect traditional crafts and innovate. At same time we have protected the development of intangible cultural heritage and achieve a win-win situation. The printing and dyeing technique is gradually updated, so as to meet the actual needs of the public. At present, many people could find their emotional sustenance on products.

At present, we have realized the environmental protection and low carbonization in the inheritance of our traditional crafts, so that people can use them healthily and improve their spiritual vitality. In the social development of human beings, global carbon dioxide emission load shows a gradually increasing trend. We are suffering from the threats of global warming, melting glaciers, sea level rise, arable land shrink and other global problems. Low-carbon lifestyle has become the most representative form of life in the human world. At the same time, it is a kind of environmental protection responsibility of sustainable development ${ }^{[7]}$. With comparative analysis, the traditional crafts are of low carbon and environmental friendly in producing products. However, the mechanized production is relatively poor in low carbon and environmental protection. Thus, the traditional crafts could fundamentally meet the needs of people's physical and mental 
health. The traditional plant fiber clothing and traditional plant dyeing essentially is a traditional craft, which is natural and environmentally friendly. It will not harm our skin. The left dyeing materials can be used to raise fish. The traditional crafts are energy-saving and environmental, so people are very fond of it.

\section{CONCLUSION}

In the process of social development, Chinese traditional crafts shall seize opportunities and face challenges. With further prosperity and development of culture, the government appeals to reform. On the above basis, it further clarify the oral imparting and physical instructions of Chinese traditional crafts, facilitate the realization of its vivid, alive and distinctive characteristics, promote the replacement of traditional selfsupporting workshop production mode with the mechanized and industrialized production mode and realize the inheritance and sustainable development of Chinese traditional crafts. Thus, Chinese traditional crafts can keep on developing. It has become the responsibility of the whole society.

\section{REFERENCES}

[1] Xu Tingting, Yu Fuye. Study on Inheritance Characteristics and Influence of Chinese Traditional Crafts. Journal of Chongqing Academy of Arts and Sciences (SOCIAL SCIENCE EDITION), Apr. 2014: 11-16.

[2] Dai Youhua. General Law of the Development of Chinese Traditional Arts and Crafts. Arts and Crafts of Zhejiang, Jan. 1996: 12-17.

[3] Wu Chao. Protection of Intellectual Properties of Chinese Traditional Crafts. Hunan University, 2012.

[4] Zhu Chunyao. Enlightenment from the Traditional Crafts Inheritance in French Historical Architecture Restoration. Tianjin University, 2012.

[5] Liu Wei, Zeng Ming. Discussion on the Development Orientation of China's Traditional Arts and Crafts. Journal of Xuzhou Institute of Architectural Technology, Jan. 2011: 44-46.

[6] Liu Shuang, Yu Xue. The Embodiment and Inheritance of National Culture in Chinese Traditional Crafts Design. Journal of Chifeng University (NATURAL SCIENCE EDITION), Jan. 2016: 156-158.

[7] Zhao Hongyun. Innovative Application of Traditional Arts and Crafts in Modern Design. Art Education Research, Mar. 2016: 98. 